\title{
Hydraulics of stream deflectors used in fish-habitat restoration schemes
}

\author{
P. M. Biron ${ }^{1}$, D. M. Carré ${ }^{2}$ \& S. J. Gaskin ${ }^{2}$ \\ ${ }^{I}$ Department of Geography, Planning and Environment, \\ Concordia University, Canada \\ ${ }^{2}$ Department of Civil Engineering and Applied Mechanics, \\ McGill University, Canada
}

\begin{abstract}
Despite the widespread use of in-stream structures in stream restoration projects to enhance the quality of physical habitat, it is only recently that the hydraulics of these structures have been studied in detail, typically using simplistic geometries in laboratory experiments. The objective of this study is to examine hydraulics around complex flow deflectors using a combination of laboratory, field and three-dimensional (3D) Computational Fluid Dynamics (CFD) approaches. In the laboratory, Acoustic Doppler Velocimeter (ADV) measurements revealed that flow overtopping the structure modifies the scour zone and bed shear stress pattern compared to a greater structure height. In the field, a 3D CFD model, which was calibrated at low flow using ADV and Particle Image Velocimetry measurements, was used to investigate both low and high flow (overtopping) conditions. A complex 3D pattern in the recirculation zones downstream of the deflectors is observed in the overtopping simulations, highlighting the limits of habitat structure studies based on depth-averaged (2D) models. The comparison with laboratory data is complicated by the fact that a dug pool was used in the field, which does not correspond to the position of the pools that developed near deflectors over a mobile bed in the laboratory. As natural rivers exhibit a wide range of discharges with various overtopping ratios, it is essential to pursue work using 3D CFD to test how different deflector height, length and angle designs affect the position and dimension of scour zones and the long-term viability of fish-habitat restoration projects.
\end{abstract}

Keywords: three-dimensional velocity, pool, bed shear stress, deflector design, overtopping, computational fluid dynamics, recirculation zone. 


\section{Introduction}

Fish-habitat restoration schemes have been widely used in the last decades as a response to declining fish population, particularly for salmonids (Fausch et al [1]; Lake et al [2]). Many of these projects use in-stream structures such as flow deflectors in an attempt to create or maintain deep pools, in the hope that this will provide suitable habitat for many fish species, with lower velocities and cooler temperatures during the summer (Mitchell et al [3]; Thompson and Stull [4]). In recent years, several researchers have examined the complex threedimensional (3D) flow field around structures such as groins, vanes, spur dikes or deflectors (Chrisohoides et al [5]; McCoy et al [6]; Koken and Constantinescu [7]). Three-dimensional numerical models are also increasingly being used to predict the flow field and scouring processes around these structures (McCoy et al $[6,8])$. However, in order for these findings to be relevant for fish-habitat restoration schemes, more fundamental knowledge is required on flow dynamics around complex in-stream geometries such as those encountered in the field, where various materials such as logs or boulders are used. This involves a better understanding of the impact of flow stage on flow dynamics around structures, as previous studies have highlighted the fact that the flow field around submerged structures is far more complicated - with intensified three-dimensionality of the flow - than that around emergent structures (Uijttewaal [9]; McCoy et al [6]). The impact of increasing both water stage and velocities around deflectors is not clear because many laboratory experiments have used constant flow intensity conditions for various overtopping ratios (e.g. Kuhnle et al [10]; Biron et al [11, 12]).

The objective of this study is to examine hydraulics around complex flow deflectors using a combination of laboratory, field and Computational Fluid Dynamics (CFD) approaches. The differences between low flow conditions, where deflectors are emergent and high flow conditions where structures are submerged, will be examined in terms of their impact on bed shear stress and flow velocity.

\section{Methodology}

The laboratory and numerical modelling work was based on a field prototype of the Nicolet River (Quebec), located approximately $200 \mathrm{~km}$ east of Montreal and draining into the St. Lawrence River. Restoration structures, mainly consisting of paired and single boulder deflectors oriented at $135^{\circ}$, were implemented gradually from 1993 to 1999 in a 14-km reach in the Appalachian headwater section of the watershed. The drainage area of the restored reach is $332 \mathrm{~km}^{2}$, with a bankfull width of about $35 \mathrm{~m}$, a bankfull discharge $(Q)$ of $95 \mathrm{~m}^{3} / \mathrm{s}$ and an average bed slope of 0.0015 . A study reach consisting of one paired boulder deflectors is under investigation since 1999. As the Nicolet project aimed at recreating fish habitat for trout as quickly as possible, a $2.5 \mathrm{~m}$-pool was dug downstream from the deflectors. Detailed bed topography surveys are obtained 
with a total station on a yearly basis since the onset of this research program. Field measurements of velocity in the vicinity of the pool were collected with an Acoustic Doppler Velocimeter (ADV). Particle Image Velocimetry (PIV) was also used at this site to obtain simultaneous surface velocities (Carré et al [13]). Low flow PIV results were successfully compared to near-surface ADV measurements. However, attempts to use PIV at high flow failed to produce adequate results, mainly because of the surface flares and standing waves which confounded the recognition of tracer particles in the PIV processing software.

Two types of deflectors were used in a $4 \mathrm{~m}$ long, $0.6 \mathrm{~m}$ wide laboratory flume (Civil Engineering Hydraulics Laboratory, McGill University) to examine flow dynamics around in-stream structures. A Plexiglas channel was inserted into the flume, reducing the flume width $(W)$ to $0.40 \mathrm{~m}$. First, two sharp-edged Plexiglas deflectors of $0.013 \mathrm{~m}$ in thickness and $0.05 \mathrm{~m}$ in length (contraction ratio (length of deflector $/ W$ ) of 0.25 ) oriented at $135^{\circ}$ were used over a mobile bed $\left(\mathrm{D}_{50}=\right.$ $1.1 \mathrm{~mm}$ ) with low-flow conditions (emergent deflectors). Details on the experimental design are provided in Biron et al [12]. The second series of experiments used a deflector design closer to the field prototype, also oriented at $135^{\circ}$ but with glued gravel on Plexiglass deflector skeletons using scaled-down deflector dimensions based on field topography surveys. The contraction ratio here was 0.50 and flow conditions were similar to bankfull conditions in the field (overtopping ratio (flow depth / deflector height) of 1.96). Velocities were also higher than for the first set of experiments, in order to examine the combined effect of increasing flow stage and velocity. Bed shear stress was calculated from the turbulent kinetic energy (TKE) approach, which has proved more accurate in a complex flow field than other methods based on mean velocities (Biron et al [11]).

The 3D CFD model Phoenics was used to run simulations of the flow field at the Nicolet River for low and high flow conditions. The software uses the finite volume approach to solve the fully 3D form of the Reynolds Averaged NavierStokes (RANS) equations in each cell of the modelling domain. The model is described in detail elsewhere (Bradbrook et al $[14,15])$ and has been used extensively in both laboratory Haltigin et al $[16,17]$ and field studies (Ferguson et al. [18]; Carré et al [13]). The bed topography survey was used to create an "object-bed" (Haltigin et al [16]). This was imported in the CFD model as a 3D object. A Cartesian grid of $291 \times 68$ x 50 in the downstream, lateral and vertical dimensions was used for the high flow condition $\left(Q=50 \mathrm{~m}^{3} / \mathrm{s}\right.$, overtopping ratio of 1.38), whereas a grid of 191 x 68 x 30 was used for a low flow condition, where discharge is similar to the ADV measurement flow condition $(\mathrm{Q}=3.06$ $\mathrm{m}^{3} / \mathrm{s}$ ). The simulations were performed using the RNG $k-\varepsilon$ turbulence model, previously shown to perform well for simulation of flows in areas affected by high shear such as regions of significant separation and recirculation (Ferguson et al [18]), as is the case near deflectors. Because steady-state simulations are used, it is not possible to compute bed shear stress from turbulent fluctuations. Thus, the law of the wall was used to compute bed shear stress from the four cells closest to the bed. 


\section{Results}

The laboratory results reveal a marked increase in bed shear stress near the deflectors (fig. 1). However, the pattern differs between the low flow, lower velocity situation (fig. 1a) and the overtopping situation with faster flow and rough deflectors (fig. 1b). The scour zones where flow depth is less than the deflector height are limited to the areas near the deflectors, whereas a single, larger pool forms for the overtopping conditions with a higher contraction ratio, although the deepest areas remain close to the deflectors.

a)

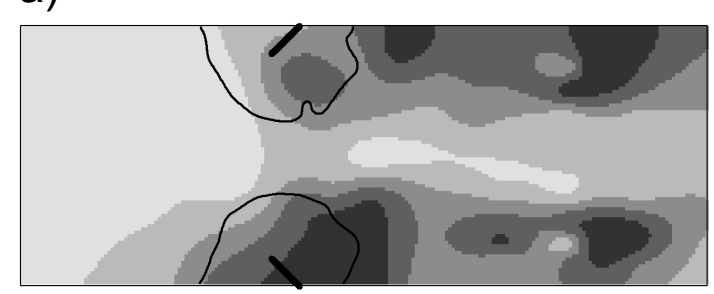

b)

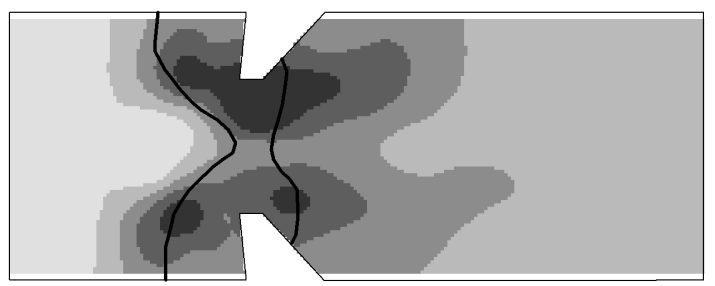

Bed shear stress

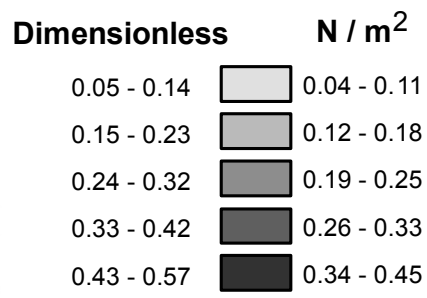

- Scour limit

Bed shear stress

\section{Dimensionless $\mathbf{N} / \mathbf{m}^{2}$}

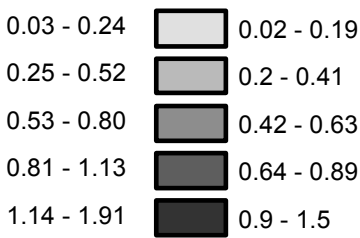

Figure 1: Laboratory bed shear stress distribution (TKE method) for a) deflectors oriented at $135^{\circ}$ with contraction ratio of 0.25 at lowflow conditions (emergent deflectors) b) deflector design oriented at $135^{\circ}$ (field prototype) with contraction ratio of 0.5 at high flow (overtopping ratio of 1.96). Dimensionless values are obtained by dividing by (Shields) critical shear stress. Flow is from left to right.

The simulated field bed shear stresses contrast markedly with the pattern observed in the laboratory (fig. 2). Note that the dug pool in the Nicolet River in the central zone does not correspond to the location of the pool in both emerged and overtopping conditions in the laboratory. At low flow, an important increase in bed shear stress is observed between the deflectors in the simulation (fig. 2a), whereas the maximum shear stress zones in the laboratory experiments were located near the structures. At high flow, the simulated flow field also reveals high shear stress values in the centre, although the maximum values are found above the deflectors (note that measurements above the deflectors could not be obtained in the laboratory because the flow was too shallow for the ADV 
sampling volume located $5 \mathrm{~cm}$ below the probe). Near-bed ADV field measurements taken at low flow reveal a pattern of accelerating flow similar to that in the simulated near-bed flow field (fig. 3a, b). For a similar flow condition, near-surface velocities obtained with Particle Image Velocimetry showed good qualitative agreement with the simulated flow field (Carré et al [13]).

The near bed velocity data obtained by the ADV as well as the simulated flow field for both low and high flow conditions show, as expected, a marked decrease in flow velocity in the recirculation zone downstream of the deflectors (fig. 3). However, unlike the low flow pattern where at all heights above the bed, there are two distinct recirculation zones downstream of deflectors (fig. 3b, 4a), simulations for high flow, overtopping condition reveal a much more complex 3D flow pattern in this separation zone (fig. 4b). The near-surface vectors are always oriented downstream (fig. 4b), with relatively high minimum velocities (around $0.30 \mathrm{~m} / \mathrm{s}$ ) above the recirculation zone observed in near-bed velocity vectors (fig. 3c).

a)
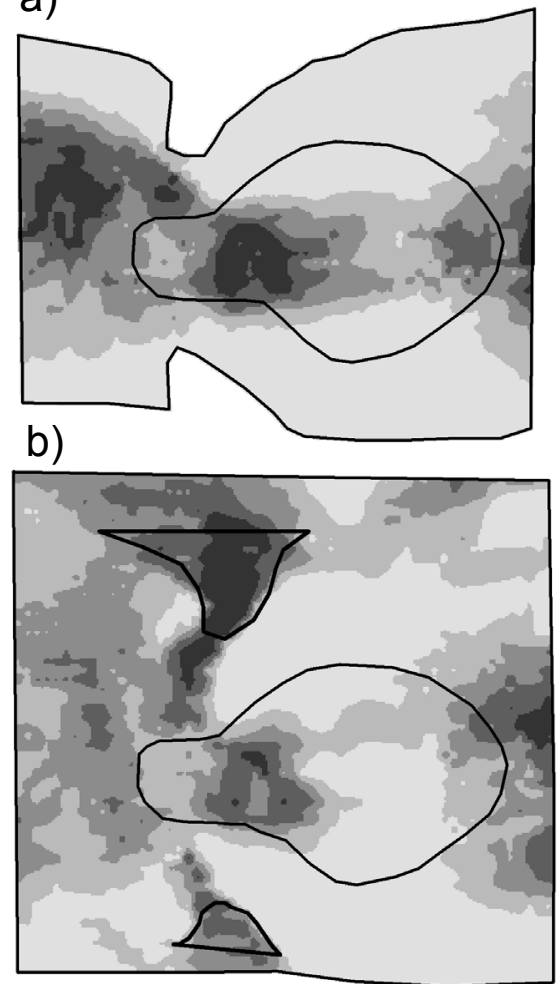

Bed shear stress Dimensionless $\quad \mathbf{N} / \mathbf{m}^{2}$

$0-0.04$

$0.04-0.12$

$0.12-0.21$

$0.21-0.33$

$0.33-0.71$

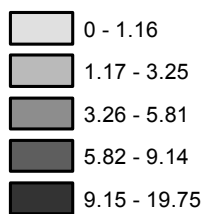

Bed shear stress Dimensionless $\mathrm{N} / \mathrm{m}^{2}$

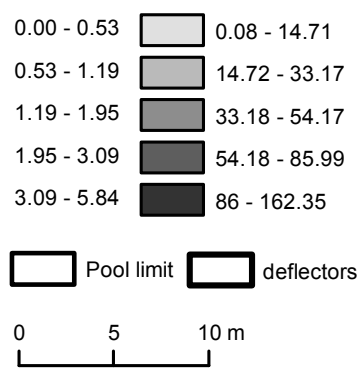

Figure 2: $\quad$ Simulated field bed shear stress (Nicolet River) obtained from the law of the wall around deflectors oriented at $135^{\circ}$ at (a) low flow conditions (emergent deflectors) and (b) high flow conditions (overtopping situation). Flow is from left to right. 

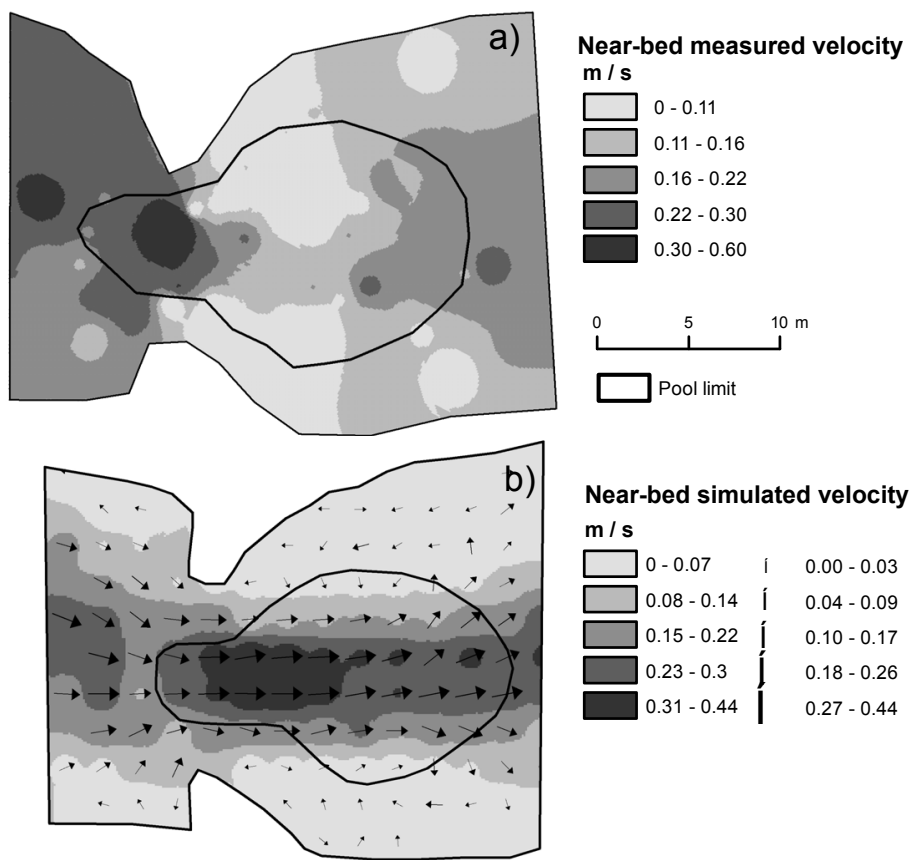

Near-bed simulated velocity $\mathrm{m} / \mathrm{s}$
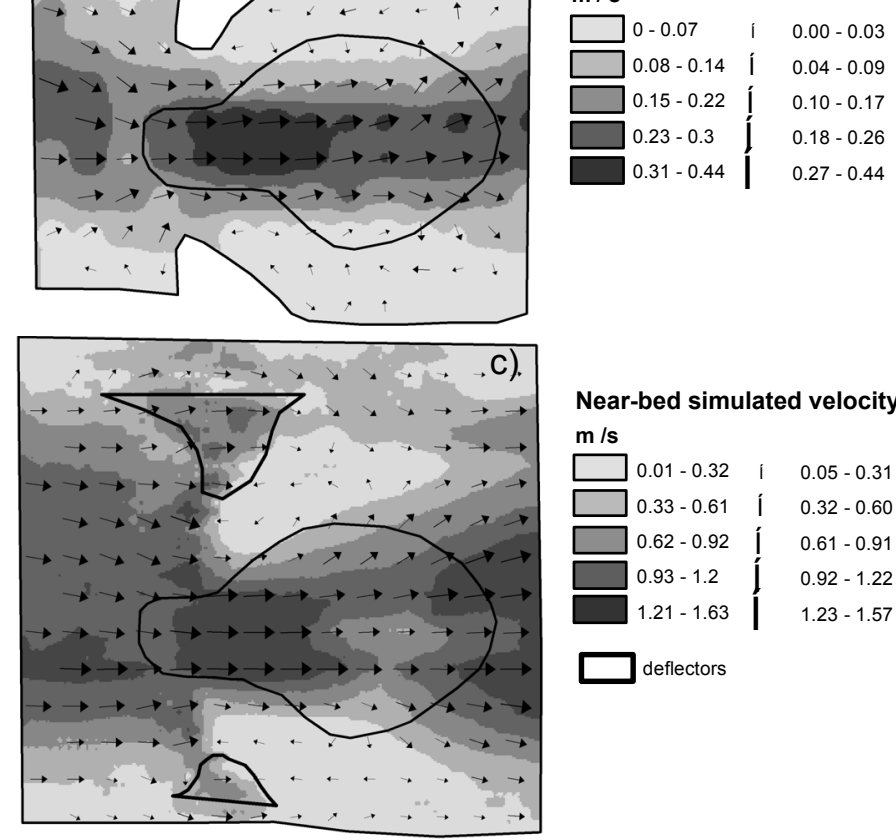

Near-bed simulated velocity

$\mathrm{m} / \mathrm{s}$

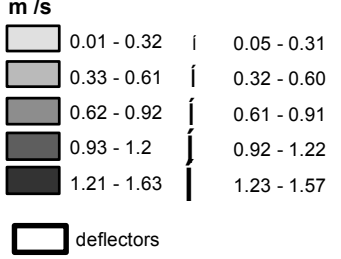

Figure 3: Near-bed velocity distribution in the Nicolet River from a) low flow field measurements (ADV), (b) low flow simulated velocities (emergent deflectors) and (c) high flow simulated velocities (overtopping situation). Flow is from left to right. 
a)

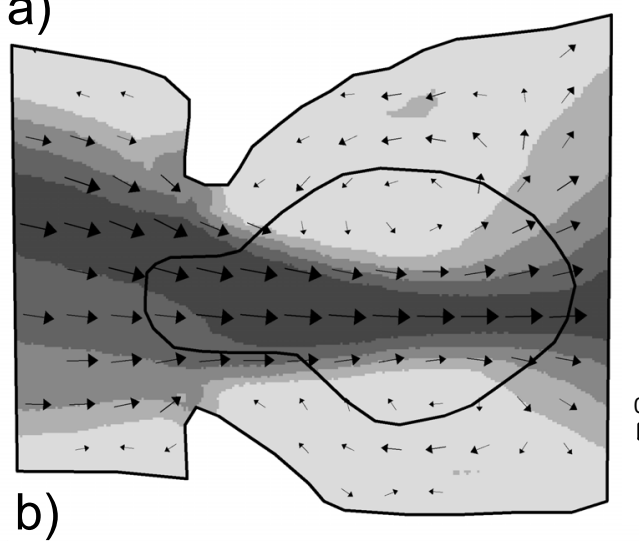

Near-surface simulated velocity

$\mathrm{m} / \mathrm{s}$

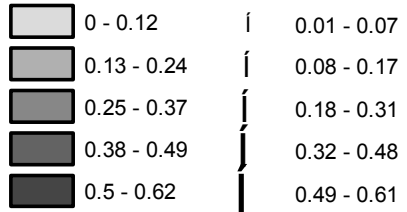
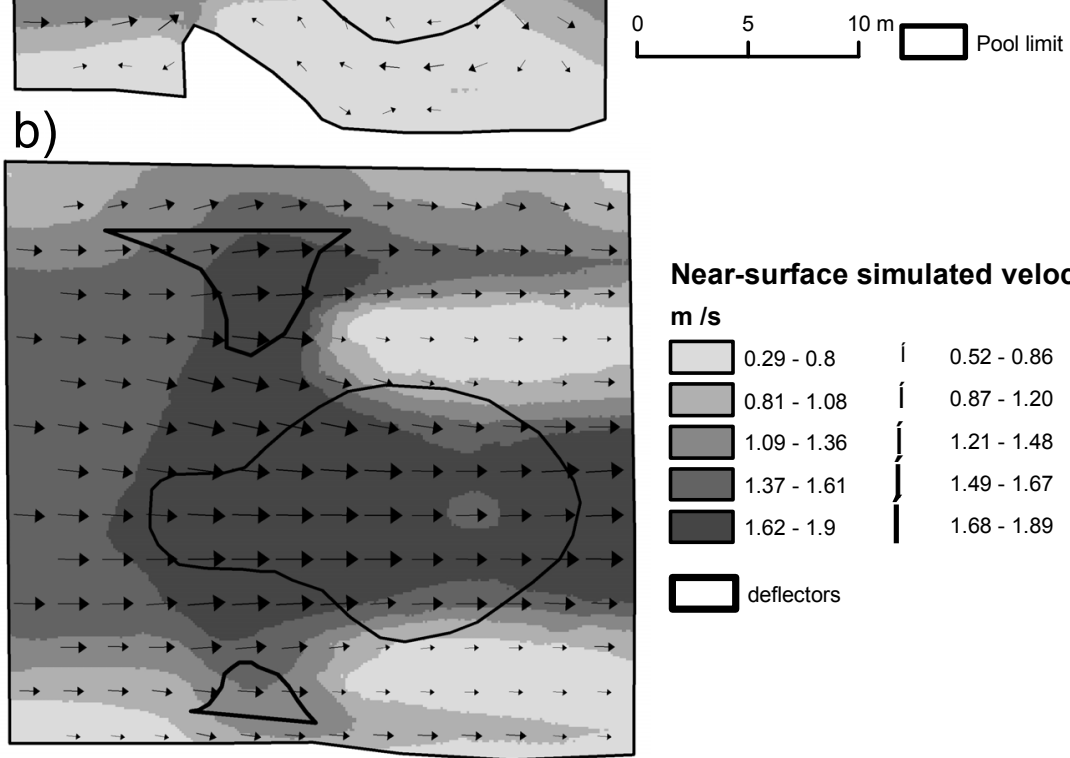

Near-surface simulated velocity

$\mathrm{m} / \mathrm{s}$

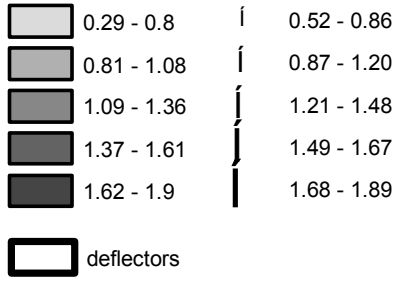

Figure 4: Near-surface simulated velocity distribution in the Nicolet River at (a) low flow conditions (emergent deflectors) and (b) high flow conditions (overtopping situation). Flow is from left to right.

\section{Discussion and conclusion}

The intensified three-dimensionality of the flow and resulting complex flow patterns for overtopping conditions compared to the flow field around emergent structures corresponds well to other laboratory observations (Uijttewaal [9]; McCoy et al [6]). Field 3D simulations for both low and high flow conditions also reveal an asymmetrical distribution of bed shear stress with larger values on the left side (fig. 2). The difference in flow dynamics and bed shear stress patterns between the left and the right bank downstream of the deflectors is attributed to size and elevation variations between deflectors, local turbulence generation and varying morphology on each side. It results in increased bedload 
transport on the left side (Carré et al [19]), which may result in future adjustments of the dug pool with time, although the pool area and volume has not changed markedly in the last 9 years (Biron et al [20]).

In nature, a range of floods of various magnitudes will occur, resulting in a high variability in overtopping ratios. Two different scenarios could arise depending on flow stage. When the flow just overtops the deflectors, an impinging jet can form a plunge pool just downstream the deflectors and scour out the bed and bank (fig. 5a). When the deflectors are drowned out, a surface jet develops, creating a horizontal displacement of water with higher velocities (fig. $5 b)$. A very complex 3D pattern downstream of the immerged deflectors is observed in both scenarios, involving highly turbulent flow field due to the flow separation, strong interactions between eddies in the mixing layers around structures and the main flow field, vortex shedding and strong adverse pressure gradients. When examining near bed simulated velocity results (fig.3c) a divergence of the flow vectors towards each side of the pool can be seen, which is very different from the straight pattern observed at the water surface (fig.4b). Upstream, bed shear stress reveals larger value due to the backed up water of the flow field around the submerged structure. Deflector roughness, especially boulder-based, increases frictional resistance at overtopping condition and amplify backwater effect. The impact of deflector roughness needs to be further investigated as the majority of studies so far have used smoother obstructions (Kuhnle et al [10]), while natural deflectors, which are frequently overtopped, are always rough (whether wood-based or boulder-based).

(a)

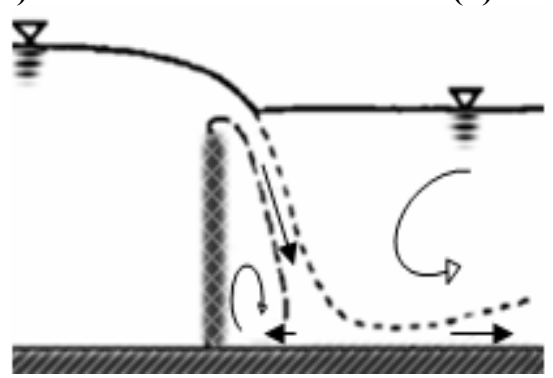

(b)

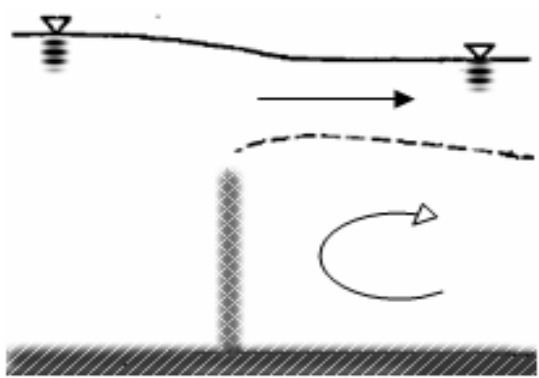

Figure 5: Overtopping flow regimes over submerged weirs (a) impinging jet (b) surface jet. Adapted from Wu and Rajaratnam [21].

The results from this study as well as previous laboratory work clearly highlight that the flow field around submerged structures can only be adequately simulated by a 3D model. Depth-averaged (2D) models do not take the vertical variability in velocity into account, which is necessary to understand the complex 3D flow field around structures. A 3D modelling approach to test different river restoration designs prior to their implementation should thus be pursued. These models should also examine in the future unsteady (such as Large Eddy Simulation (LES)) rather than time-averaged simulations to 
accurately describe the complex flow and the dynamics of the large-scale turbulence around deflector-like structures, especially when they are submerged (McCoy et al [8]; Koken and Constantinescu [7]). This would allow turbulent estimates of bed shear stress (Reynolds or TKE) to be obtained. These methods may reveal larger shear stress values downstream of the deflectors, such as those observed in the laboratory, although previous field estimates based on the TKE method at low flow (from ADV measurements) did not show this (Carré et al [19], fig. 6). An accurate estimation of bed shear stress and bedload transport is clearly essential for assessing restoration projects and improve their success rate.

\section{Acknowledgements}

This research was funded by Canada Natural Sciences and Engineering Research Council (NSERC) grants (Biron and Gaskin).

\section{References}

[1] Fausch, K.D., Torgersen, C.E., Baxter, C.V. \& Hiram, W.L., Landscapes to riverscapes: bridging the gap between research and conservation of stream fishes. BioScience, 52(6), pp. 2-16, 2002.

[2] Lake, P.S., Bond, N. \& Reich, P., Linking ecological theory with stream restoration. Freshwater Biology, 52(4), pp. 597-615, 2007.

[3] Mitchell, J., McKinley, R.S., Power, G. \& Scruton, D.A., Evaluation of Atlantic salmon parr responses to habitat improvement structures in an experimental channel in Newfoundland, Canada. Regulated Rivers: Research and Management, 14(1), pp. 25-39, 1998.

[4] Thompson, D. M. \& G. N. Stull., The use of habitat structures in channel restoration: a historical perspective. Géographie Physique et Quaternaire, 56, pp. 45-60, 2002.

[5] Chrisohoides, A., Sotiropoulos, F. \& Sturm, T.W., Coherent structures in flat-bed abutment flow: computational fluid dynamics simulations and experiments. Journal of Hydraulic Engineering, 129(3), pp. 177-186, 2003.

[6] McCoy, A., Constantinescu, G. \& Weber, L., A numerical investigation of coherent structures and mass exchange processes in channel flow with two lateral submerged groynes. Water Resources Research, 43, 2007.

[7] Koken, M. \& Constantinescu, G., An investigation of the flow and scour mechanisms around isolated spur dikes in a shallow open channel: 1 . Conditions corresponding to the initiation of the erosion and deposition process. Water Resources Research, 44, 2008.

[8] McCoy, A., Constantinescu, G. \& Weber, L., Numerical investigation of flow hydrodynamics in a channel with a series of groynes. Journal of Hydraulic Engineering, 134(2), pp. 157-172, 2008.

[9] Uijttewaal, W., Effects of groyne layout on the flow in groyne fields: Laboratory experiments, Journal of Hydraulic Engineering, 131, pp. 782$794,2005$. 
[10] Kuhnle, R. A., Alonso, C. V., \& Shields, F. D., Jr., Geometry of scour holes associated with $90^{\circ}$ spur dikes. Journal of Hydraulic Engineering, 125(9), pp. 972-978, 1999.

[11] Biron, P.M., Robson, C., Lapointe, M.F. \& Gaskin, S.J., Deflector designs for fish habitat restoration. Environmental Management, 33(1), pp. 25-35, 2004.

[12] Biron, P.M., Robson, C., Lapointe, M.F. \& Gaskin, S.J., Three-dimensional flow dynamics around deflectors. River Research and Applications, 21, pp. 961-975, 2005.

[13] Carré, D.M., Biron, P.M. \& Gaskin, S.J., A three-dimensional model of flow dynamics around paired deflectors for fish habitat enhancement. Proceedings of the RiverFlow 2006 Conference, eds. Ferreira, R.M.L., Alves, E.C.T.L., Leal, J.G.A.B. \& Cardosa, A.H., Taylor and Francis: Lisbon, Portugal, pp. 1889-1895, 2006.

[14] Bradbrook, K.F., Biron, P.M., Lane, S.N., Richards, K.S. \& Roy, A.G., Investigation of controls on secondary circulation in a simple confluence geometry using a three-dimensional numerical model. Hydrological Processes 12, pp.1371-1396, 1998.

[15] Bradbrook, K.F., Lane, S.N., Biron, P.M. \& Roy, A.G., Role of bed discordance at asymmetrical river confluences. Journal of Hydraulic Engineering, ASCE, 127(5), pp. 351-368, 2001.

[16] Haltigin, T.W., Biron, P.M. \& Lapointe, M.F., Three-dimensional numerical simulation of flow around stream deflectors: The effects of obstruction angle and length. Journal of Hydraulic Research, 45(2), pp. 227-238, 2007a.

[17] Haltigin, T.W., Biron, P.M. \& Lapointe, M.F., Predicting equilibrium scour hole geometry near angled stream deflectors using a three-dimensional numerical model. Journal of Hydraulic Engineering, ASCE, 133(8), pp. 983-988, 2007b.

[18] Ferguson, R.I., Parsons, D.R., Lane, S.N. \& Hardy, R.J., Flow in meander bends with recirculation at the inner bank. Water Resources Research, 39(11), pp. 1322-1334, 2003.

[19] Carré, D.M., Biron, P.M. \& Gaskin, S.J., Flow dynamics and bedload sediment transport around paired deflectors for fish habitat enhancement: a field study in the Nicolet River. Canadian Journal of Civil Engineering, 34(6), pp. 761-769, 2007.

[20] Biron, P.M., Carré, D.M., Carver, R.B., Rodrigue-Gervais, K. and Whiteway, S. (in review) Combining field, laboratory and three-dimensional numerical modelling approaches to improve our understanding of fish habitat restoration schemes. In: Stream Restoration in Dynamic Fluvial Systems: Scientific Approaches, Analyses, and Tools, Simon, A., Bennett, S.J., Castro, J.M. and Thorne, C. (Eds).

[21] Wu, S. \& Rajaratnam, N., Submerged flow regimes of rectangular sharpcrested weirs. Journal of Hydraulic Engineering, ASCE, 122(7), pp. 412414, 1996. 